\title{
Strategic Planning, External Environment and Performance of County Governments in Kenya
}

\author{
Catherine N. David \\ Post graduate student, \\ The Management University of Africa \\ Dr. Washington Okeyo \\ Deputy Vice-Chancellor - Academic, Research and Extension, \\ The Management University of Africa
}

\begin{abstract}
The purpose of the study was to determine the effect of effect of strategic planning on organizational performance of Nairobi County. Descriptive research design was adopted in this study which targeted a total of 246 employees of Nairobi County government of whom 23 were top level managers, 61 middle level managers and 162 low level managers. Data was collected using structured questionnaire administered through drop and pick from a sample of 80 employees who were selected using stratified and sequential random sampling methods. Correlation and linear regression analysis were used to analyze the data. Regression results revealed that there was a positive and significant relationship between strategic planning and performance of the county government. Regression results further revealed that external environment has a positive and significant effect on performance of county government. In addition, external environment moderate the relationship between strategic planning and performance of county government. The study recommends that strategic formulation should be a top priority activity at every county government. County government should also employ top-bottom communication during the strategic plan implementation process. In addition, the county government should ensure they have enough competent staff to implement strategic initiatives. Adequate financial resources should also be allocated towards strategy control in their county. Performance indicators and targets should also be clearly defined and communicated within the county. In addition, employees of the county should comply with the county by laws. The county government should therefore do proper environmental scanning so as to improve their performance. The county government should also comply with the parliamentary Acts formulated from the Kenya's 2010 constitution.
\end{abstract}

Key words: strategic planning, organizational performance

\section{INTRODUCTION}

Decentralization has been seen as an important tool in revenue performance and therefore instrumental in providing services closer to people in large and densely populated economies such as China, the US and some European countries through federal arrangements (Clegg \& Greg, 2010). According to Rosenbaum (2013) the worldwide governance trend is towards decentralization. In the United States of America, for example, the governance structure is highly decentralized. The US has 50 state governments and approximately 85,000 local governments. Both national and devolved governments are independent with taxing authority and, in many cases, a quite high degree of autonomy within the geographic sphere in which they function. In Africa, there are about 15,000 local governments; Asia has about 26,000 local governments, while Latin America has about 17,000 local governments (Rosenbaum, 2013). 
In Africa, many countries have carried out reforms aimed at decentralizing the political, administrative, and fiscal structures of the public sector. The need to transform the structure of governance is informed by the view that decentralization increases the overall efficiency and responsiveness of the public sector in providing services, an outcome that enhances economic development and contributes to a reduction in regional disparities decentralization has advanced considerably in the last two decades (Amusa \& Mabugu, 2016). Moreover, many central governments in Africa have initiated or deepened processes to transfer authority, power, responsibilities, and resources to sub-national levels. The African countries that have decentralized include Kenya, Botswana, Burkina Faso, Ethiopia, Ghana, Mali, Mozambique, Nigeria, South Africa, Tanzania, and Uganda (Dickovick \& Riedl, 2010).

In Kenya, a new constitution was promulgated in the year 2010 which split the country into forty seven (47) counties one of which is Nairobi City County. The county was formed on the same boundaries of what was initially recognized as Nairobi Province and got its first governor in 2013.

\section{Strategic planning}

Strategic planning is branded as the arrangement of thoughts and deeds that result to formulations of implementations of plans that are intended to achieve an entity objective (Pearce \& Robinson, 2003). The essential objective of strategic planning is to manage a firm in setting out its vital aim, needs and center itself towards achieving the same (Kotter, 1996). Strategic planning is made up of putting into place vital procedures to control a circumstance in order to attain better and idealistic result for an entity. Strategic planning pin points direction for some unit like, financial focuses, human resource, marketing and businesses. Strategic planning is usually effective when there is a unison agreement in the mission, and when the task relies on, expertise and technology is put into consideration

Organizations undertake strategic planning for various reasons (Pathfinder International, 2014). Strategic planning not only help build trust within an organization, build on the team but it also helps the organization to move in a unison direction, anticipate for change and deal with it According to Aosa (2011) those firms that put strategic planning on their map are able to generate a lot of income as compared to those that don't, in addition strategic planning also help in making informed decisions on things as compared to firms that don't.

Organizations that practice strategic planning also have a higher sales return, significant productivity and efficiency as compared to organization without strategic planning. Strategic plans also challenge the status quo and allow management to put a lot of emphasis on the objectives concerning the future direction of the organization (Pathfinder International, 2014). There are even instances when a clearly thought out strategic plan can be used as marketing tool and can encourage donor support for the organization.

According to Pearce and Robbinson (2008) effective Strategic planning practices involve formulation of vision and mission statement, performance of environmental analysis, objective setting and finally strategy selection occasionally lot of firms tend to wait after they have undergone one or more cycle of strategic planning before coming up with the vision of the entity. Established organization and communities, on the other hand develop visions of what they want to be the start of the process to develop a unison agreement on values and purpose that guide on emerging issues and strategy identification (Thompson, 2014).

Vision describes the firm's aspirations of what it really wants to be. Pitts (2003) notes that vision statements are designed to capture the imagination of the public and as well galvanize 
the efforts of employees at all levels such that its emotional appeal challenges them to commit their full energies and minds to believe it is the best. Most organizations may want to wait until they go through one or more cycles of strategic planning before developing a detailed vision. New organizations, and communities, however, often establish a vision of what/where they want to be at the beginning of the process to establish consensus on purpose and values to guide issue and strategy identification. The vision portrays a company's future business scope; where we are going or want to be (Thompson et al., 2004).

Objective setting is one of the most prominent and basic tools used by both individuals and organizations to assist in setting their direction and in accomplishing it. Objective setting always go in hand with goal setting. Goals are the broad, long-term accomplishments that an organization wants to attain, achieve or where it wants to be. They provide the overall context for what the vision tries to achieve (Nickels et al., 2000). They are powerful tools that break the vision statement into specific tasks and actions to attain desired results across the organization. They function as the yardstick for tracking an organization's performance or progress (Thompson et al., 2004). Successful companies and other organizations (public sector and nonprofit entities) often set both long- and short-term goals, not only for sales, products, and service development but also for improving quality, reducing errors, becoming more customer-focused, and building better internal and public relations. Therefore for the success of the Organization, Drucker (1999) emphasizes that strategic plans must be designed to support objectives.

Strategy selection is the way by which a firm chooses the best course of doing things in order to obtain desirable results. This ways are crucial as they determine the end result to which the firm will get. Strategic plans ought to be made aware to all subordinates so as to align their action in the direction of achieving the company's objectives (Pearce, Robinson \& Subramanian, 2000). Strategy formulation pushes an organization to be conversant with the immediate environment and be prepared for the any changes that can come with it. Strategy formulation forces an organization to carefully look at the changing environment and to be prepared for the possible changes that may occur. A strategic plan also enables an organization to evaluate its resources, allocate budgets, and determine the most effective plan for maximizing ROI (return on investment).

\section{County governments}

In the year 2010, Kenya promulgated a new constitutional dispensation that advocated for a devolved system of governance. The main purpose of this important action was to address failures linked to quality of governance such as corruption, economic stagnation, poverty, development inequalities and episodic instability. This has currently led to the establishment of 47 County governments in the country that are charged with the responsibility of providing various services to the local people. Key among the responsibilities of the County governments is the implementation of the devolution strategy. Nairobi City County is one of the 47 County governments that were established through the promulgation of the new constitution in the year 2010. The County came into existence in March 2013 on the same boundaries of what was formerly known as Nairobi province. Nairobi County has an approximate population of 3.5 million people but the population continues to increase at a rate of $3 \%$ each year.

\section{Statement of the Problem}

Since the beginning of devolved system of governance in Kenya, county governments have experienced a number of performance challenges (Hornsby, 2013). Most citizens in Nairobi County have expressed their dissatisfaction with the services offered by Nairobi County 
government for example heavy traffic in the city, poor roads, water rationing, garbage collection among many others. In the recent Tifa opinion polls county ranking, Nairobi was ranked second last performing county (Tifa Polls Report, 2017). Don (2014) suggests that lack of good strategic planning is one of the major causes of poor performance in Nairobi County. Lack of good strategic planning leaders to lack of vision, slow budget approvals, lack of clear individual role, lack of alignment with the organization strategic plan, lack of employee involvement, poor staffing level, and ineffective communication during strategy implementation and lack of coordination of activities during strategy implementation in Nairobi County. This has made Nairobi county government lag behind on service delivery. Strategic planning is a very important activity in organizations. Research however shows that strategic planning can be used as a tool to improve organizational performance. Organizations that undertake good strategic planning have better performance as compared to organizations with poor or no strategic planning practices. This study sought to determine the relationship between strategic planning and organizational performance in Nairobi County government and the role of external environment in this relationship.

\section{LITERATURE REVIEW}

\section{Theoretical Literature review}

This study was anchored on resource based view theory which was proposed by (Wernerfelt, 1984). Wernerfelt (1984) borrowed ideas from Penrose (1959) who pioneered the thinking behind resource based view. The theory argues that for a firm to be recognized as more competitive than other firms, it ought to have a relatively higher position in the market. Other firms should also not already be using its strategy in the market place (Penrose, 1959). The resource-based view argues that strategic management is very vital and brings the firm's ability to have an upper hand. Outperforming performance is connected to capabilities and resources which are costly to obtain (Barney, 1991). Arguing from a point of view that strategic assets are evenly distributed across all firms, Barney (1991) went ahead to reveal existence of association between a firm's upper hand and its strategic resources. Four elements that enable a firm resources impact significantly to it having an upper hand include value, rareness, inimitability, and non-substitutability.

The resource-based view however has been critiqued. According to Priem and Butler (2001), the RBV lacks managerial explanation on how thing should be handled similarly its validity is questionable. In spite of showing that managers can develop and acquire resources that can help an organization have an upper hand it fails to show they can do so (Connor, 2002). Priem and Butler (2001) and Collins (1994), also argues that the RBV is regressive in nature. In case a firm has capabilities that it can use for better result but does not use those capabilities another firm can use those capabilities and overtake the firm thus having an upper hand. Collins (1994) calls this second-order capabilities). As per Kraaijenbrink et al. (2010), However Resource Based view applicability is limited to small firms and only applies to large firm that can sustain themselves in upper hand, this limitation makes sustainability of lower firms to be deemed unachievable, making them fall short of RBV (Kraaijenbrink et al., 2010).

The Resource Based View of organizations combines strategy and management of a firm making it key in ensuring the firm's has a competitive advantage. The use of Resource base view in management involves identifying capabilities and assets that can give the firm an upper hand during competition. In this paper the theory is helpful as it helps the management beware of their environment both macro and micro, and come up with effective strategic planning procedures to positively shape the performance of the organization. Through the analysis of the critics of the theory, the paper is able to recommend the best theories or combine a couple of relevant theories that can help in the solving of the research problem. 


\section{Empirical literature review}

Julian (2013) conducted a study on non-governmental organizations (NGOs): the relationship between strategic planning and organization's performance. The data being qualitative in nature content analysis was used. The study found out that there was a positive contribution of strategic planning directly to organizational performance. The study concludes that strategy planning and organization performance in Action Aid Kenya to ensure strategy alignment has to involve drawing from a global context, prioritize. The result finalized that approaches and final results in weighing down strategic planning effectiveness and firm performance are totally different, this confirms the argument that picking the most convenient approach to measuring relationship between strategic planning and organization performance ought to be done with uttermost carefulness.

Debrah's (2012) results on the effect of strategic planning on performance and operations of the agricultural development bank showed that, for the various features of a managed bank there was a relative improvement in the bank. The study however showed that for the bottom up infrastructure put into place there was lack of familiarity with the employees in the bank. This was due to employees lacking keenness about the programs or lack putting consideration toward the programs. The research recommended that so as to achieve the best result for the ADB then emphasis ought to be put so as to familiarize the employees with the infrastructures put into place.

Sophia (2015) conducted a study on effects of strategic planning on organizational growth: A Case Study of Kenya Medical Research Institute, and used qualitative research design in which the questionnaires were filled by the selected, heads of department, middle level managers and general staff members of Kenya Medical Research Foundation (KEMRI). The findings show that for there to be growth in the organization strategic planning has to be implemented well. Strategic planning was deemed to be of importance in the organization and was upheld as appropriate this shows that KEMRI used strategic planning for evaluating and identifying objectives of the organization that were long term and also in distribution of assets and monitoring and evaluation of progress to ensure growth.

\section{Gaps in Literature Review}

Several gaps were identified from literature which included; methodological, conceptual and contextual gap. For example, Julian (2013) conducted a study and the nature of information gathered was subjective and was hence examined utilizing content examination system. The current research uses (quantitative) descriptive technique to analyze data, thus this presented a methodological gap. Julian (2013) focused on Action Aid Kenya.

\section{Hypotheses of the study}

The study was guided by the following hypotheses:

$\mathbf{H}_{\mathbf{0 1}}$ : Strategic planning has no significant effect on Performance of Nairobi county government $\mathbf{H}_{02}$ : External environment has no moderating effect on the relationship between strategic planning and organizational performance

\section{Conceptual Framework}

This study is conceptualized with three variables, an independent, a moderating and a dependent variable. The conceptualization depicts strategic planning as the independent, external environment as the moderating variable which modifies the relationship between strategic planning and performance of Nairobi County Government. These relationships are summarized in Figure 2.1. 


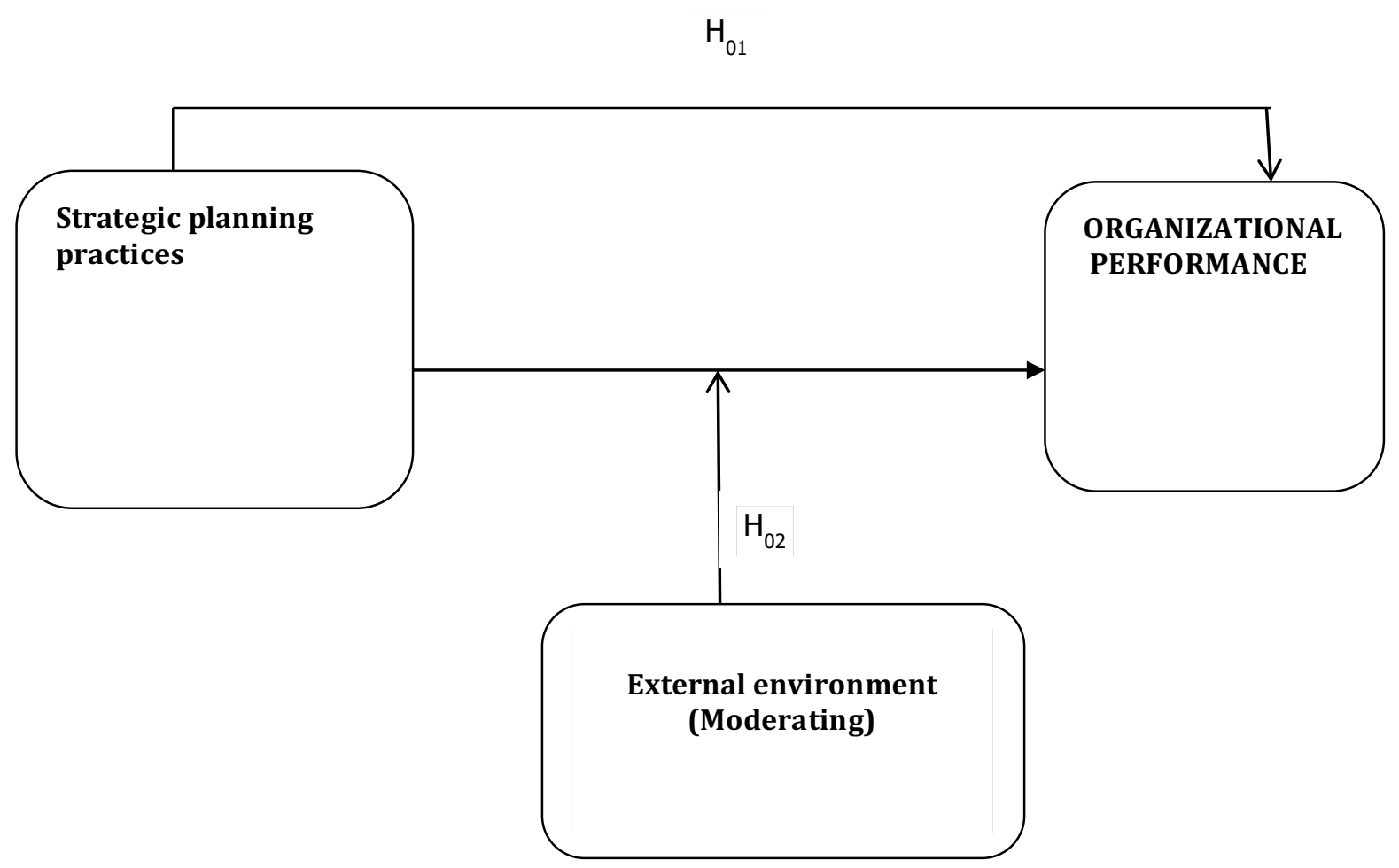

Figure 2.1: Conceptual Diagram

\section{RESEARCH METHODOLOGY}

Descriptive research design was adopted in this study Olusola et al (2013). Population comprised of 23 top level managers, 61 middle level managers and 162 low level managers in Nairobi county government. Since the population was less than 10,000, the Fisher et al, (2003) formula was utilized. The sample size was therefore 80 managers selected through stratified random sampling. The strata will be top level managers, middle level managers and low level managers. The study used primary and secondary data collected through structured questionnaires and content analysis respectively. Quantitative data was coded, classified, and entered into SPSS. Descriptive statistics, correlation coefficient and linear regression techniques within SPSS were used analyze the data while Microsoft excel was used to draw tables and charts.

\section{Demographic and preliminary analysis}

\section{RESULTS AND DISCUSSION}

Analysis by gender show that majority (71\%) of the respondents male while the rest (29\%) female. The results of the study are thus more skewed towards male gender. Age-wise, majority (63\%) were aged between 41 - 50 years, $22 \%$ over 50 years, $9 \%$ were between 31 40 years while only $6 \%$ were between 18 - 30 years. This implies that most employees working for the county government of Nairobi were mature aged above 41 years. Further analysis by level of education indicates that $59 \%$ of the respondents had a bachelor degree, $27 \%$ had ordinary diploma, and $10 \%$ had a master degree while $4 \%$ had a certificate. This implies that most employees studied were educated and thus had the capacity to improve performance of the county. The study adopted descriptive survey design targeting a population of 246 from whom a sample of 80 was drawn using Cochran's (1977) formula. Data was collected with questionnaire using drop and pick method. A total of 80 questionnaire were filled and 68 returned giving a response rate of $85 \%$. Descriptive statistics, correlation analysis, and regression analysis techniques were used to analyse data. The analysis was done using statistical package for social sciences (SPSS) version 24. 


\section{Descriptive statistics}

Descriptive statistics show that strategic planning had a mean of 3.56 and a standard deviation of 1.21 implying that the most respondents' opinions were within a maximum of three showing that diversity in views. External environment had a mean of 3.76 and a standard deviation of 1.28 also indicating diversity in respondents' opinions. Performance on the other hand had a mean of 3.87 and a standard deviation of 1.07 which indicates lesser variation in opinions of respondents. Correlation analysis of the variables all returned significant associations. Strategic planning and performance had $r=0.595$ and $p \leq 0.05$, external environment and organizational performance had $\mathrm{r}=0.569$ and $\mathrm{p} \leq 0.05$, and strategic planning and external environment had $\mathrm{r}=0.538$ and $\mathrm{p} \leq 0.05$.

\section{Hypothesis testing}

All the hypotheses of this study were tested using linear regression analysis techniques. The tests were done in SPSS version 24 at 95\% confidence interval. The linear regression model used during hypothesis testing was of the form:

Where:

$$
\mathrm{Y}=\alpha+\beta \mathrm{X}_{1}+\beta \mathrm{X}_{2}+\ldots \ldots+\beta \mathrm{X}_{\mathrm{n}}+\mathrm{e}
$$

Y= Organizational performance

$\mathrm{X}_{\mathrm{i}}=$ independent variables

$\mathrm{e}=$ error term

Table 4.1 shows results for the tests of hypothesis one which stated that "there is no significant relationship between strategic planning and performance of Nairobi County government".

Table 4.1: Model summary

\begin{tabular}{ccccc}
\hline Model & R & R Square & Adjusted R Square & Std. Error of the Estimate \\
\hline 1 & $.595 a$ & 0.354 & 0.344 & 0.62183 \\
\hline
\end{tabular}

Predictors: (Constant), strategic planning

This model summary table presents an $\mathrm{R}^{2}$ value of 0.354 which means that strategic planning can explain up to $35.4 \%$ of the total variability in the organizational performance. The remaining $65.6 \%$ of the variation may be explained by other factors including chance.

Further tests of Analysis of Variance (ANOVA) were performed on the model and the results obtained are presented in Table 4.2.

Table 4.2: Analysis of Variance

\begin{tabular}{lccccc}
\hline & Sum of Squares & df & Mean Square & F & Sig. \\
\hline Regression & 13.968 & 1 & 13.968 & 36.123 & $.000 \mathrm{~b}$ \\
Residual & 25.521 & 66 & 0.387 & & \\
Total & 39.489 & 67 & & & \\
\hline
\end{tabular}

ANOVA results in Table 4.2 indicate that the model is statistically significant $(\mathrm{p} \leq 0.05)$ and strong $(\mathrm{F}=36.123)$. This indicates that strategic planning is significantly related to organizational.

Results of tests of regression coefficients are presented in Table 4.3. 
Table 4.3: Regression coefficients

\begin{tabular}{lcccc}
\hline & $\beta$ & Std. Error & t & Sig. \\
\hline (Constant) & 1.012 & 0.481 & 2.105 & 0.039 \\
strategic planning & 0.814 & 0.135 & 6.01 & 0.000 \\
\hline
\end{tabular}

From the results in Table 4.7, regression coefficient $(\beta)$ of strategic planning is 0.814 which implies that the relationship between strategic planning and organizational performance is very strong and significant $(\mathrm{p}=0.000)$. Therefore, the null hypothesis which stated that there is no significant effect of strategic planning on performance of Nairobi County government is rejected. The study therefore concludes that there is a significant effect of strategic planning on performance of Nairobi County government. These findings agree with those of Julian (2013) who established that strategic planning has a significant effect on organizational performance.

Further tests were done for hypothesis two which stated that "external environment has no moderating effect on the relationship between strategic planning and organizational performance of Nairobi County government" and the results presented in Table 4.4.

Table 4.4: Model summary

\begin{tabular}{lcccc}
\hline Model & R & R Square & Adjusted R Square & Std. Error of the Estimate \\
\hline 1 & $.595 \mathrm{a}$ & 0.354 & 0.344 & 0.62183 \\
2 & $.664 \mathrm{~b}$ & 0.441 & 0.424 & 0.58279 \\
3 & $.665 \mathrm{c}$ & 0.442 & 0.416 & 0.58653 \\
\hline
\end{tabular}

The $\mathrm{R}^{2}$ of 0.354 was obtained in this model. This showed that model 1 could explain 35.4 per cent of variance in the dependent variable (performance) with an incremental variance.

The findings from table 4.14 also showed that when staff training was added as a moderator, the $\mathrm{R}^{2}$ rose to $44.1 \%$

Finally, to investigate how the external environment moderates the relationship between strategic planning and performance, the interaction terms of the independent variable and the moderator (strategic planning) were entered in the regression model to obtain model 3. The $\mathrm{R}^{2}$ improved to $44.2 \%$

Table 4.5: ANOVA

\begin{tabular}{lccccc}
\hline & Sum of Squares & Df & Mean Square & F & Sig. \\
\hline Regression & 13.968 & 1 & 13.968 & 36.123 & $.000^{\mathrm{b}}$ \\
Residual & 25.521 & 66 & 0.387 & & \\
Total & 39.489 & 67 & & & $.000^{\mathrm{c}}$ \\
\hline Regression & 17.412 & 2 & 8.706 & 25.632 & \\
Residual & 22.077 & 65 & 0.34 & & $.000^{\mathrm{d}}$ \\
Total & 39.489 & 67 & & & \\
\hline Regression & 17.471 & 3 & 5.824 & 16.928 & \\
Residual & 22.017 & 64 & 0.344 & & \\
Total & 39.489 & 67 & & & \\
\hline
\end{tabular}

All the independent variables (strategic planning) were jointly found to have a positive and significant relationship with performance $(\mathrm{p}<0.05)$. 
The findings from table 4.10 also showed that independent variables and the moderating variable were significantly and jointly related to organizational performance $(\mathrm{p}<0.05)$.

Finally, external environment was found to have a moderating effect on the relationship between strategic planning and performance $(\mathrm{p}<0.05)$.

Table 4.6: Regression of Coefficients

\begin{tabular}{lrrrl}
\hline & B & Std. Error & \multicolumn{1}{c}{ t } & Sig. \\
\hline (Constant) & 1.012 & 0.481 & 2.105 & 0.039 \\
strategic planning & 0.814 & 0.135 & 6.01 & 0.000 \\
\hline (Constant) & 0.435 & 0.486 & 0.896 & 0.374 \\
strategic planning & 0.556 & 0.15 & 3.696 & 0.000 \\
External environment & 0.393 & 0.123 & 3.184 & 0.002 \\
\hline (Constant) & -0.538 & 2.392 & -0.225 & 0.823 \\
strategic planning & 0.109 & 0.048 & 2.265 & 0.025 \\
external environment & 0.138 & 0.043 & 3.191 & 0.002 \\
Planning*environment & 0.259 & 0.046 & 5.643 & 0.000 \\
\hline
\end{tabular}

From the results above external environment was found to have a moderating effect on the relationship between strategic planning and performance $(p=0.000)$. Therefore the null hypothesis that external environment has no moderating effect on the on the relationship between organizational performance of Nairobi city county government was rejected

$$
\mathrm{Y}=-0.538+0.109 \mathrm{X}_{1}+0.138 \mathrm{M}+0.259 \mathrm{X}_{1} * \mathrm{M}+\varepsilon
$$

Where $Y$ is organizational performance

$\mathrm{X} 1$ is strategic planning

$M$ is external environment

$\varepsilon$ is the error term

\section{Summary of major findings}

\section{SUMMARY, CONCLUSIONS AND RECOMMENDATIONS}

The first objective of the study was to establish the effect of strategic planning on organizational performance of Nairobi city county government. The findings indicate that Nairobi County's strategic behavior and choices were in line with environmental developments and this is incorporated in strategy formulation. In addition, members of staff are briefed and taken through the strategic management plan before implementation. Furthermore, managers of the county are motivated to support implementation of strategies in the county government. From correlation results, strategic planning have a positive association with performance of county government. In addition, regression results revealed that there was a positive and significant relationship between strategic planning and performance of the county Government. Hypothesis results also revealed that strategic planning has a significant effect on organizational performance of Nairobi city county government. These findings agreed with that of Julian (2013) who found that strategic planning have a significant effect on organizational performance. These findings further agrees with that of Sophia (2015) who conducted a study on effects of strategic planning on organizational performance and found that strategic planning have a positive and significant effect on organizational performance. 
The second objective was to determine the moderating effect of external environment on the relationship between strategic planning and organizational performance of Nairobi city county government. Regression results revealed that external environment has a positive and significant effect on performance of county Government. In addition, external environment moderate the relationship between strategic planning and performance of county government. These findings agreed with that of Jane (2014) who found that external organizational environment have a positive and significant effect on performance of community-based HIV and AIDS organizations in Nairobi County, Kenya. These findings further agrees with that of Adeola (2016) who found that external business environment (economic, political, legal, sociocultural environment, demographic, natural, technological, global and financial environment) have a significant influence on MSMEs Performance in Nigeria.

\section{CONCLUSION}

The study concludes that strategic planning have a positive and significant effect on organizational performance of the county Government. In addition Nairobi county government have the financial capacity to implement all the strategic planning strategies. The study also concludes that Nairobi county strategic behavior and choices were in line with environmental developments and this is incorporated in strategy formulation. In addition, managers of the county are motivated to support implementation of strategies in the county government. In addition, government policies have been enhanced in Nairobi county operations. Social cultural and economic factors also determine the level of performance of the county and also affect economic development of the county.

The study will benefit Nairobi County government through understanding various challenges experienced in strategic planning by Nairobi County government; the study will point out weak operations once and manage their resources and capabilities towards that goal. The study will benefit the county government establishments to learn and understand various challenges which face most of the country(s) strategic planning; this will create an opportunity to unearth the critical service areas which are the core activity of any county government and its operations.

From a theory point of view, the study will come up with a framework of strategic planning and its effect on performance of the county. Such a framework will be available for future theory building and empirical testing. In particular, the applicability of various theories discussed in literature will be tested in this study.

\section{RECOMMENDATION}

The study recommends that strategic formulation should be a top priority activity at every county government. County government should also employ top-bottom communication during the strategic plan implementation process. In addition, the county government should ensure they have enough competent staff to implement strategic initiatives. Adequate financial resources should also be allocated towards strategy control in their county. Performance indicators and targets should also be clearly defined and communicated within the county.

In addition, employees of the county should comply with the county by laws. The county government should therefore do proper environmental scanning so as to improve their performance. The county governments should also comply with the Acts formulated from the new constitution. 


\section{SUGGESTED AREAS FOR FUTURE RESEARCH}

Further study should focus on the research gaps identified in this study. The current study focused on effect of strategic planning on performance of Nairobi county government. Thus area for further studies could consider other county governments in Kenya for the purpose of making a comparison of the findings with those of the current study.

Since the R squared was not $100 \%$ it seems there are other strategic planning practices that were not addressed by the study. Other studies should therefore focus on other strategic planning practices that may affect performance of Nairobi county government.

\section{References}

Andersen, T.J. (2004). Integrating decentralized strategy making and strategic planning processes in dynamic environments. Journal of Management Studies, 41 (8), 1271-99.

Aosa, E. (2011). Strategic Management within Kenya Firms. DBA Africa Management Review. 1 (1), 25-36.

Barney, J. (1991). Firm resources and sustained competitive advantage. Journal of management, 17(1), 99-120.

Debrah, K. P. (2012). The effect of strategic planning on the performance and operations of the Agricultural Development Bank (Doctoral dissertation).

Don, O. S. (2014). Challenges of strategy implementation at the Nairobi county government (Doctoral dissertation, University Of Nairobi).

Julian, O. (2013). Relationship between strategic planning and organization's performance in Non-Governmental Organizations (NGOS): A Case Of Actionaid, Kenya (Unpublished MBA Project School of Business, University of Nairobi).

Kraaijenbrink, J., Spender, J. C., \& Groen, A. J. (2010). The resource-based view: a review and assessment of its critiques. Journal of management, 36(1), 349-372.

Sophia, O. M., \& Owuor, D. (2015). Effects of Strategic Planning on Organizational Growth. (A Case Study of Kenya Medical Research Institute, Kemri). International Journal of Scientific and Research Publications.

Tapinos, E., Dyson, R.G., Meadows, M., (2005). The impact of performance measurement in strategic planning. International Journal of productivity and performance management 54.

Wernerfelt, B. (1984). A resource-based view of the firm. Strategic management journal, 5(2), 171-180. 